\title{
Spontaneous subdural haematoma in a healthy young male
}

\author{
Paul M Brennan, Eleanor Fuller, Mano Shanmuganathan, Peter Keston, loannis Fouyas \\ Deparment of Clinical Neurosciences, Western General Hospital, Edinburgh, Midlothian, UK \\ Correspondence to Mr Paul Brennan, paul.brennan@ed.ac.uk
}

\begin{abstract}
Summary
The authors present an unusual case of a healthy young male who developed a spontaneous subdural haematoma. Headache was followed by blurring of vision and left upper limb symptoms. The diagnosis was made from a CT scan. Symptoms resolved with surgical decompression. The authors explore the risk factors and pathophysiology implicated in this condition. The authors demonstrate that apparently 'healthy' pursuits can have significant consequences, but the physician must also exclude serious underlying risk factors for bleeding, which the authors discuss.
\end{abstract}

\section{BACKGROUND}

There are few documented cases of spontaneous subdural haematoma $(\mathrm{SDH})$ in healthy young men and we have presented this unusual case to highlight the possible mechanisms of haematoma formation. In doing so, we highlight the potential risks of apparently healthy activities, but also emphasise the importance a thorough history and examination play in excluding potentially serious underlying conditions that could also lead to non-traumatic SDH.

\section{CASE PRESENTATION}

A previously well 37-year-old male complained of sudden onset blurring of his left lateral visual field, resolving after a few minutes, accompanied by left upper limb numbness and weakness which resolved after $20 \mathrm{~min}$.

Over the preceding 2 weeks he had experienced intermittent headache radiating from behind his eyes to the vertex of his head and into his teeth, with no sensory or motor dysfunction. Episodes of headache initially lasted 24 $h$, but increased in frequency and severity, although they did not interfere with his running or saxophone playing.

There was no history of trauma.

\section{INVESTIGATIONS}

Cranial CT identified an isodense subdural collection (figure 1). Haematological, biochemical and clotting investigations were within normal limits.

With no history of trauma, catheter angiography was performed to exclude a vascular risk factor for the subdural haematoma, such as arteriovenous malformation. Angiography was unremarkable.

\section{TREATMENT}

Right frontal burr hole haematoma drainage resulted in initial symptom resolution. The patient re-presented 2 weeks later with recurrent headache. A repeat CT scan (figure 2) identified a recurrent isodense subdural haemorrhage. A mini-craniotomy was formed from the original burr hole to evacuate the recurrent clot. No bleeding point was identified. The patient recovered uneventfully.

\section{DISCUSSION}

There are few documented cases of spontaneous SDH in healthy young men. In one review of 21 patients with nontraumatic SDH, risk factors included hypertension, vascular malformations, neoplasia such as haematological malignancies causing thrombocytopaenia, solid tumour dural metastases, infection, hypervitaminosis, coagulopathy and alcoholism. ${ }^{1}$ Bleeding from cerebral artery aneurysms or cortical arteries has also been reported. None of these were present in this patient. Cranial imaging (CT and MRI) can identify many of these pathologies. Where uncertainty remains intraoperatively, dural biopsies and subdural fluid can be collected for pathological analysis.

We will review the possible pathogenesis of subdural bleeding in a healthy young man.

$\mathrm{SDH}$ result from bleeding of the subdural portion of bridging veins, which has been identified as more fragile than the subarachnoid portion of the vein. In trauma, anteroposterior acceleration or deceleration of the head can cause traction of the bridging veins, which rupture at this weak point in the subarachnoid space. Cerebral atrophy, from ageing or alcoholism, accentuates the degree of traction on the bridging veins.

In the absence of trauma, subdural bleeding might instead result from sudden increase in intravenous pressure. This can happen when forceable exhalation occurs against a closed glottis (a Valsalva manoeuvre), for example during coughing or defecation, but also while blowing into high resistance instruments, such as a saxophone. Non-invasive measurements have identified a rise in intraocular pressure in such musicians, reflecting increased intravenous pressure. ${ }^{2} 3$ Our patient was playing his saxaphone for several hours a night prior to admission.

However, in addition to his musical abilities, our patient was also a marathon runner. There are several ways in which athletic pursuits could precipitate subdural bleeding.

First, spontaneous SDH has been described in anabolic steroid-dependent weight lifters. ${ }^{4}$ Anabolic steroids are proposed to cause vascular remodelling, and therefore vascular weakness that increases susceptibility to bleeding. 


\section{BMJ Case Reports}

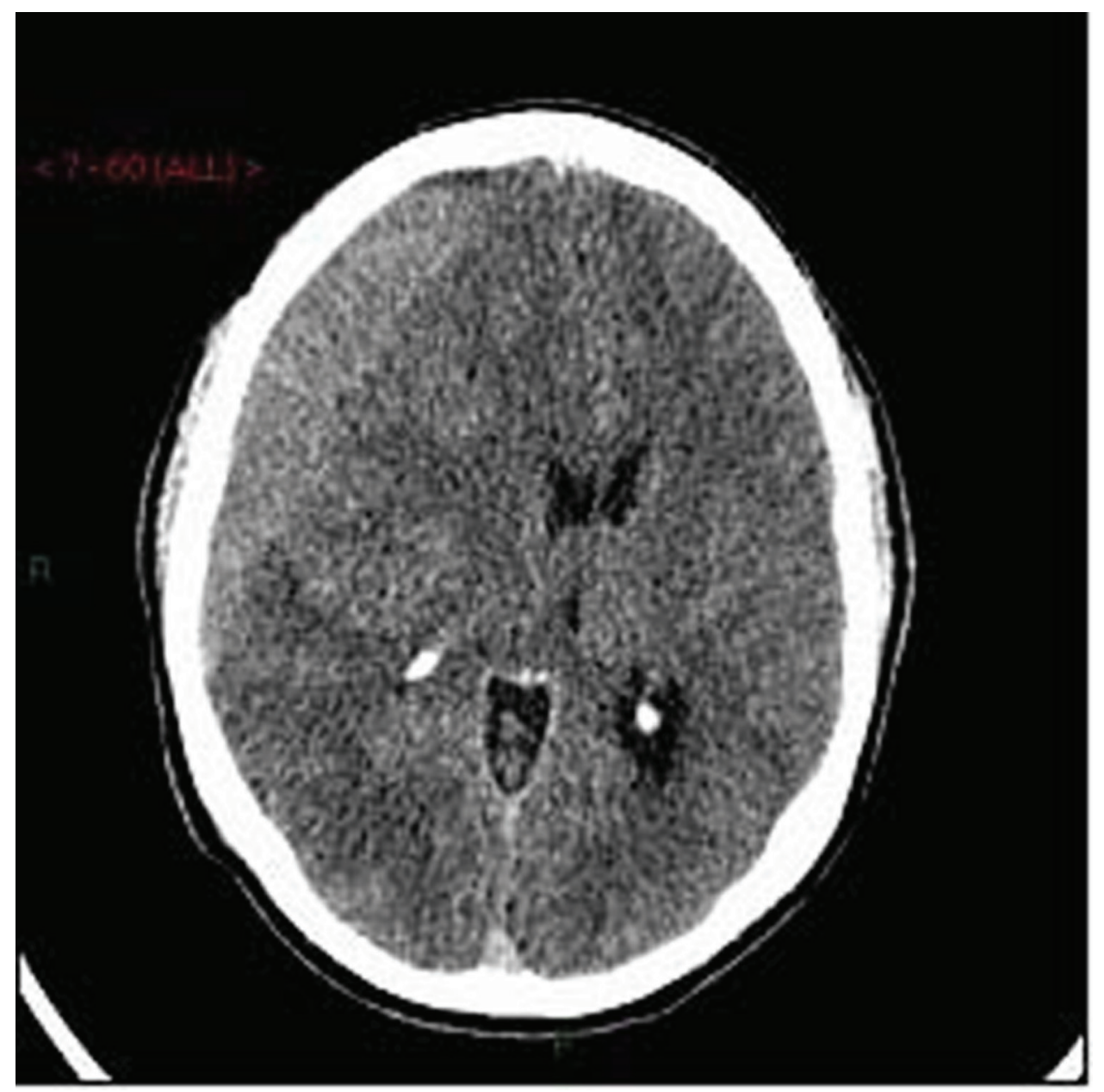

Figure 1 Non-enhanced CT head scan showing a right side subdural collection with marked mass effect and ventricular effacement. Maximally $28 \mathrm{~mm}$ in depth, with $13 \mathrm{~mm}$ deviation of midline structures to the left side. Ipsilateral cortical sulci effaced.

Our patient did not use steroids or indeed any other recreational drugs, such as cocaine, which have also been implicated in subdural haematomas.

Second, many athletes engage in weight training, which can potentially result in subdural bleeding through generation of a Valsalva manoeuvre. For example, in the 'clean and jerk' lift, the athlete first squats and inhales as the weight is lifted to the chest from the floor. They then exhale against a closed glottis as the weight is moved into position above their head, (a Valsalva manoeuvre). Following this there is also postexertional intracranial hypotension, when the weight is dropped, because rapid exhalation and muscle relaxation occurs. Intravenous pressure then falls, and intracranial hypotension reduces brain volume, leading to cerebral retraction and increase risk of bridging vein bleeding..$^{5}$ Our patient did not lift weights.

Third, intracranial hypotension, which is thought to account for $10 \%$ of all spontaneous subdural haematomas, can occur following exercise. ${ }^{6}$ Bouts of submaximal dynamic exercise result in systemic vascular hypotension. In one study, systolic blood pressure reduced by $20 \mathrm{~mm} \mathrm{Hg}$ 10 min following exercise. ${ }^{7}$

Intracranial hypotension can also be secondary to systemic hypotension resulting from loss of circulating blood volume, such as accompanies dehydration. The average marathon runner loses $5 \%$ body weight and $6.5 \%$ of plasma volume while racing. ${ }^{8}$ Our patient was not clinically dehydrated on admission and had normal renal function biochemically. However, it is possible that an episode of acute and transient dehydration while running resulted in intracranial hypotenion and precipitated a subdural bleed. Following rehydration the risk of further subdural bleeding would decrease.

Other potential causes of intracranial hypotension (such as shunt over drainage) are not directly relevant to our healthy patient, although one does merit brief mention, namely intracranial hypotention secondary to spontaneous dural tear and cerebrospinal fluid (CSF) leak. However, since our patient's symptoms settled with haematoma drainage we did not investigate this further. A persistent dural CSF leak would be expected to result in multiple and recurrent haematoma even after drainage.

Another area of risk for subdural bleeding is coagulopathy. Our patient had 'normal clotting function', but standard investigations do not test all aspects of clotting. In particular, platelet function is not tested. Impaired platelet aggregation secondary to non-steroidal anti-inflammatory drugs (NSAIDs) was a significant risk factor for non-traumatic SDH in one study. ${ }^{9}$ Interestingly, our patient took regular NSAIDs for muscle aches during training. NSAIDs 


\section{BMJ Case Reports}

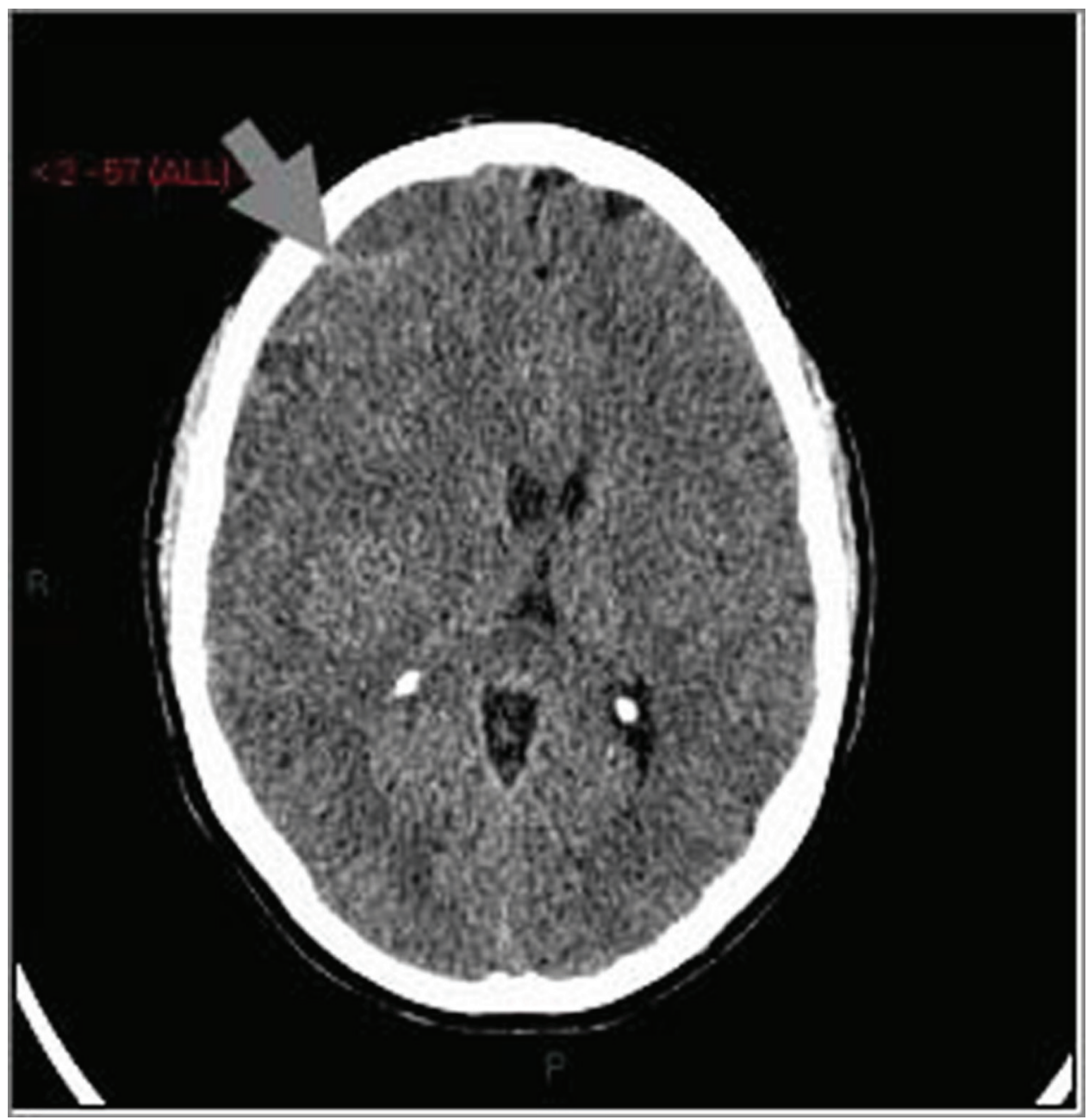

Figure 2 Repeat non-enhanced CT head scan showing a right sided recurrence of isodense septated subdural haematoma, with evidence of small recent haemorrhage (arrow).

act by inhibiting cyclooxygenase, producing thromboxane A2, which inhibits platelet function, increasing bleeding risk.

\section{Learning points}

- Seemingly healthy pursuits can result in serious complications.

- SDH may result from intracranial hypotension secondary to systemic vascular hypotension, arising from dehydration acquired while marathon training.

- A thorough history and examination is required to exclude potentially serious underlying conditions that could also lead to non-traumatic SDH.

- Preoperative imaging (eg, MRI and CT) and intraoperative collection of dural tissue and subdural fluid are also valuable in identifying risk factors for spontaneous SDH.

Competing interests None.

Patient consent Obtained.

\section{REFERENCES}

1. Hesselbrock R, Sawaya R, Means ED. Acute spontaneous subdural hematoma. Surg Neurol 1984;21:363-6.

2. Haykowsky MJ, Eves ND, R Warburton DE, et al. Resistance exercise, the Valsalva maneuver, and cerebrovascular transmural pressure. Med Sci Sports Exerc 2003;35:65-8

3. Schuman JS, Massicotte EC, Connolly S, et al. Increased intraocular pressure and visual field defects in high resistance wind instrument players. Ophthalmology 2000;107:127-33.

4. Alaraj AM, Chamoun RB, Dahdaleh NS, et al. Spontaneous subdural haematoma in anabolic steroids dependent weight lifters: reports of two cases and review of literature. Acta Neurochir (Wien) 2005;147:85-7; discussion 87-8.

5. Dickerman RD, Morgan J. Pathogenesis of subdural hematoma in healthy athletes: postexertional intracranial hypotension? Acta Neurochir (Wien) 2005: 147:349-50.

6. de Noronha RJ, Sharrack B, Hadjivassiliou M, et al. Subdural haematoma: a potentially serious consequence of spontaneous intracranial hypotension. $J$ Neurol Neurosurg Psychiatr 2003:74:752-5

7. MacDonald JR, MacDougall JD, Interisano SA, et al. Hypotension following mild bouts of resistance exercise and submaximal dynamic exercise. Eur $J$ Appl Physiol Occup Physiol 1999;79:148-54.

8. Maughan RJ, Whiting PH, Davidson RJ. Estimation of plasma volume changes during marathon running. Br J Sports Med 1985;19:138-41.

9. Lindvall P, Koskinen LO. Anticoagulants and antiplatelet agents and the risk of development and recurrence of chronic subdural haematomas. J Clin Neurosci 2009:16:1287-90. 


\section{BMJ Case Reports}

This pdf has been created automatically from the final edited text and images.

Copyright 2011 BMJ Publishing Group. All rights reserved. For permission to reuse any of this content visit http://group.bmj.com/group/rights-licensing/permissions.

BMJ Case Report Fellows may re-use this article for personal use and teaching without any further permission.

Please cite this article as follows (you will need to access the article online to obtain the date of publication).

Brennan PM, Fuller E, Shanmuganathan M, Keston P, Fouyas I. Spontaneous subdural haematoma in a healthy young male. BMJ Case Reports 2011; 10.1136/bcr.01.2011.3694, date of publication

Become a Fellow of BMJ Case Reports today and you can:

- Submit as many cases as you like

- Enjoy fast sympathetic peer review and rapid publication of accepted articles

- Access all the published articles

Re-use any of the published material for personal use and teaching without further permission

For information on Institutional Fellowships contact consortiasales@bmjgroup.com

Visit casereports.bmj.com for more articles like this and to become a Fellow 